\title{
Controle biológico de Bursaphelenchus cocophilus por rizobactérias e Trichoderma spp.
}

\author{
Carina Melo da SILVA ${ }^{1}$, Cássia Cristina Chaves PINHEIRO ${ }^{2}$, Ieda Alana Leite de SOUSA², \\ Paulo Manoel Pontes LINS ${ }^{3}$, Gisele Barata da SILVA ${ }^{1,2}$, Eudes de Arruda Carvalho ${ }^{4}$ \\ ${ }^{1}$ Programa de Pós-Graduação em Agronomia, Universidade Federal Rural da Amazônia, Belém, PA, Brasil. \\ ${ }^{2}$ Instituto de Ciências Agrárias, Universidade Federal Rural da Amazônia, Belém, PA, Brasil. \\ ${ }^{3}$ Sococo Agroindústria da Amazônia SA, Ananindeua, PA, Brasil. \\ ${ }^{4}$ Embrapa Recursos Genéticos e Biotecnologia, Brasília, DF, Brasil. \\ *E-mail: carinamelosilva@gmail.com
}

Recebido em janeiro/2017; Aceito em março/2018.

RESUMO: O objetivo do trabalho foi avaliar o potencial de rizobactérias e Trichoderma spp. no controle biológico de Bursaphelenchus cocophilus. Foram avaliados 19 isolados de Pseudomonas spp. (P), 29 de Bacillus spp. (B) e 27 de Trichoderma spp. (T), obtidos de plantio comercial. Os isolados foram caracterizados quanto a produção de compostos bioquímicos. Foi avaliada a taxa de mortalidade de $B$. cocophilus in vitro e in vivo, neste último realizou-se também a quantificação das enzimas relacionadas à patogênese. Os isolados B14 e P41 proporcionaram $69 \%$ e $56 \%$ de taxa de mortalidade de nematoides, respectivamente e foram tanto proteolíticos como solubilizadores de fosfato. Os isolados T41 e T54 apresentaram 96\% de mortalidade de $B$. cocophilus in vitro e foram produtores de quitinases, protease e sideróforos. No experimento in vivo, os isolados de rizobactérias B14, B23 e P23 promoveram maior taxa de mortalidade do B. cocophilus do que os demais tratamentos. As mudas de coqueiro inoculadas com o B. cocophilus apresentaram aumento nas atividades das enzimas peroxidases, quitinase e $\beta$-1,3-glucanases, quando comparadas com a testemunha (mudas não inoculadas). Os isolados B41, P14, T41 e T54 apresentaram-se como potenciais agentes de controle biológico do B. cocophilus.

Palavras-chave: anel vermelho, antagonismo, nematoide.

\section{Biologic control of Bursaphelenchus cocophilus with rhizobacteria and Trichoderma isolates}

\begin{abstract}
The purpose of this study was to evaluate the potential of rhizobacteria Pseudomonas spp. and Bacillus spp. and Trichoderma spp. isolates on the biological control of the nematode Bursaphelenchus cocophilus. The potential biological control isolates (48 rhizobacteria and 27 Trichoderma spp.) were characterized biochemically. The biological control experiments were carried out "in vitro" and "in vivo", and in the later one, the mortality rate of the nematodes and the pathogenesis related enzymes were evaluated. Rhizobacterial isolates B14 and P41 provided a high nematode mortality rate (69\% and 56\%, respectively) and both were proteolytic and phosphate solubilizers. In the "in vivo" experiment, rhizobacterial isolates B14, B23 and P23 tested the highest mortality rates of $B$. cocophilus than the isolates of Trichoderma spp. and of the control as coconut saplings challenged with $B$. cocophilus showed indices higher in enzyme activities, peroxidases, chitinase and $\beta$-1,3-glucanases when compared to witness (seedling not inoculated). The isolates B41, P14, T41 and T54 were presented as potential biological control agents of B. cocophilus.
\end{abstract}

Keywords: red ring, antagonism, nematode.

\section{INTRODUÇÃO}

A cultura do coqueiro (Cocos nucifera L.) apresenta grande importância econômica mundial, tendo sua produção distribuída principalmente entre a Ásia (83\%), América $(8,7 \%)$, África $(3,4 \%)$ e Oceania $(4,8 \%)$. O Brasil é o quarto maior produtor de coco do mundo com área plantada de 250.554 mil.ha $^{-1}$ (FAO, 2014). No entanto, a produtividade do coqueiro pode ser limitada por várias doenças, dentre as quais está o anel vermelho, cujo agente etiológico é o nematoide Bursaphelenchus cocophilus (COBB) Baujard. (GERBER; GIBLIN-DAVIS, 1990), um endoparasita migrador, que pode infectar o coqueiro pelo contato de raízes de planta infectada com planta sadia, por meio de ferramentas contaminadas e pelo inseto vetor (Rhynchophorus palmarum), resultando na morte da planta (AGRIOS, 2005).
O processo de infecção do nematoide inicia com a penetração nas raízes e/ou na parte aérea do coqueiro, estimulando a liberação de enzimas que matam as células adjacentes, resultando na oclusão nos vasos do xilema. Como sintoma interno, há formação de uma faixa circular necrótica (anel) de 2 a $5 \mathrm{~cm}$ de diâmetro de cor laranja-vermelho, que pode progredir para o colapso dos vasos do estipe (caule), levando à morte da planta e os sintomas externos iniciam com a coloração amarelo ouro das folhas basais, seguida de necrose e quebra da ráquis e, com o progresso da doença, as folhas verdes centrais se dobram, secam e a planta morre (AGRIOS, 2005)

O método mais eficiente para a evitar a dispersão da população do $B$. cocophilus é a captura massal do inseto vetor, em armadilhas com feromônio (GERBER; GIBLIN- 
DAVIS, 1990). Não há cultivares ou híbridos resistentes à doença disponíveis para o plantio e a aplicação de nematicidas químicos não está regulamentada no Brasil (AGROFIT, 2017), além de que as aplicações desses produtos em culturas perenes não resultam em controle efetivo, podendo se tornar inviáveis economicamente.

O controle biológico consiste do emprego de microrganismos benéficos ativos, possibilitando 0 antagonismo ou parasitismo direto do patógeno através da produção ou ativação de compostos nas plantas, como quitinases, glucanases ( $\beta$-1,3-glucanases), proteases e sideróforos pelos agentes de controle biológico (CHEN et al., 2015). A secreção dessas enzimas hidrolisa os componentes da parede celular do patógeno, tais como a quitina, glucano e celulose (LUNGE; PATIL, 2012). Desta forma, o controle biológico pode ser uma alternativa para o manejo integrado da doença anel vermelho.

Além das rizobactérias, fungos do gênero Trichoderma podem produzir enzimas e antibióticos para atuar no controle de patógenos e, em alguns casos, são considerados indutores de resistência bióticos, constituindo-se, por isso, em importantes agentes de controle biológico de doenças em plantas (AGRAWAL; KOTASTHANE, 2012; LUNGE; PATIL, 2012).

O fungo Trichoderma spp. pode liberar enzimas de degradação como quitinases, glucanases ( $\beta$-1,3-glucanases) e proteases (SHARON et al. 2001; SAHEBANI; HADAVI, 2008), além de atuar como produtores de sideróforos, ligantes específicos de $\mathrm{Fe}$ (III), que desempenham a função de solubilizar especificamente ferro, em presença de outros íons metálicos e estão relacionados à capacidade de competição com outros microrganismos, pois permitem o sequestro de ferro no solo, fator determinante na competição em ambiente onde a disponibilidade de ferro é limitada (BENITE; MACHADO, 2002; VITTONE, 2008).

Estudos evidenciaram a ação de microrganismos como o Trichoderma spp. sobre espécies de nematoides em diferentes patossistemas. Affokpon et al. (2011) avaliaram 17 isolados de Trichoderma spp. e observaram que cinco isolados que reduziram em até $80 \%$ a população de $M$. incognita nas culturas do tomate e cenoura. Isolados de bactérias do gênero Bacillus spp. e Pseudomonas spp. podem apresentar capacidade de invadir os tecidos internos das plantas e de colonizar seu interior, agindo sobre os nematoides no solo e na planta hospedeira (MACHADO et al., 2012).

Estudos evidenciaram a ação de rizobactérias no controle de diversas espécies de fitonematoides. Rizobactérias dos gêneros Pseudomonas e Bacillus reduziram a população de Radopholus similis, nematoide da bananeira (CHAVES et al., 2009) e Heterodera filipjevi, nematoide da cultura do trigo (ZHANG et al., 2016). Entretanto, não há registros de controle biológico do nematoide Bursaphelenchus cocophilus.

Dada à importância econômico-social da cultura do coqueiro bem como os danos provocado pela doença do anel vermelho à cultura, essa pesquisa teve como objetivo avaliar o potencial biológico de rizobactérias e Trichoderma spp. no controle do fitonematoide Bursaphelenchus cocophilus.

\section{MATERIAL E MÉTODOS}

As amostras de solo e de raízes para isolamentos de rizobactérias, fungos com potencial antagonista e do nematoide $B$. cocophilus, foram obtidas a partir de amostras coletadas na rizosfera de coqueiros de plantio comercial, localizado no município de Moju, estado do Pará, sob as coordenadas geográficas de $02^{\circ} 07^{\prime} 11^{\prime \prime} \mathrm{S}$ e $048^{\circ} 38^{\prime} 45^{\prime \prime} \mathrm{W}$, sendo encaminhadas para o Laboratório de Fitopatologia da Embrapa Amazônia Oriental em Belém, Pará.

Foi realizado o processo de obtenção das rizobactérias pelo método de diluição seriada (SANHUEZA; MELO, 2007). Após 48 h, para confirmação do gênero, as colônias foram submetidas à câmara escura sob luz UV de $365 \mathrm{~nm}$, para avaliação da fluorescência e ao teste de Ryu (KOH a 3\%) seguindo Ryu (1940) para a confirmação da característica gram negativa de Pseudomonas spp. e gram positiva de Bacillus spp. Os isolados de rizobactérias obtidos foram repicados e preservados em microtubos criogênicos contendo água destilada esterilizada, com quatro replicatas.

$\mathrm{O}$ isolamento dos fungos Trichoderma spp. foi realizado pelo método de diluição seriada (LUNGE; PATIL, 2012). As placas foram mantidas a $25{ }^{\circ} \mathrm{C}$ sob regime de luz claro contínuo, após 48 horas, foi realizada a repicagem das colônias para meio de cultura BDA. Os isolados de Trichoderma spp. foram preservados em tubos contendo água destilada esterilizada.

Os isolados de rizobactérias dos gêneros Bacillus e Pseudomonas foram repicados para os meios NA e King B, respectivamente, para a classificação morfológica e caracterização bioquímica (solubilizadores de fosfato, sideróforos e produtores de protease). $\mathrm{E}$ os isolados fúngicos foram repicados para o meio BDA para a caracterização bioquímica (produtores de protease, de quitinase e sideróforos).

As colônias bacterianas foram classificadas quanto à cor (branca, creme, creme escuro, amarelo, amarelo-escuro e vermelha), forma (puntiforme, circular, irregular, rizoide e fuso), elevação (achatada, elevada, convexa e ondulada), borda (inteiro, ondulado, lobado e erosado), superfície (lisa e rugosa) e consistência (viscosa, seca, aquosa e gomosa) (KLEMENT et al., 1990).

A habilidade das bactérias para solubilização de fosfato foi avaliada com meio de cultura á base de $\mathrm{CaCl}_{2}$ e $\mathrm{K}_{2} \mathrm{HPO}_{4}$ sendo considerado solubilizadores de fosfato as colônias que apresentaram halos e para produção de quitinase utilizou-se meio de cultura contendo quitina coloidal, consideradas produtoras dessas enzimas as colônias que formaram uma zona clara em torno da colônia (VASCONCELLOS, 2010). $\mathrm{O}$ teste de protease foi realizado de acordo com Berg et al. (2002A), utilizando o meio de cultura TSA (ágar triptona de soja) com leite (500 mL/L de meio TSA), sendo avaliada a presença de zonas claras no meio.

Os isolados de Trichoderma spp. foram avaliados quanto à produção de quitinase, protease e sideróforos. $\mathrm{O}$ teste para quitinase foi conduzido segundo a metodologia de Agrawal e Kotasthane, (2012), sendo considerados positivos os isolados que apresentaram formação de halo com coloração avermelhada. A produção de sideróforos foi realizada pela técnica do cromo azurol S (CAS) de acordo com Schwyn e Neilands (1987), sendo avaliada a alteração de cor da solução de azulada para amarelo avermelhada. Os isolados produtores de protease foram avaliados utilizando-se meio ágar-leite (BERG et al., 2002B), os isolados que apresentaram halo transparente foram caracterizados como produtores de protease,

Para os experimentos de controle biológico do $B$. Cocophilus in vitro e in vivo foram realizadas suspensões 
bacterianas, ajustando-se a concentração final em $1,5 \times 10^{8}$ Unidade Formadora de Colônias (UFC), utilizando-se $10 \mathrm{~mL}$ para os experimentos in vitro e $50 \mathrm{~mL}$ para in vivo, utilizando o aparelho espectofotômetro (Spectrum SP 2000UV) em absorbância, no comprimento de onda de 600 $\mathrm{nm}$. Enquanto que para os fungos Trichoderma spp. foram ajustadas as suspensões para concentração de $10^{8}$ esporos.mL ${ }^{1}$ aferido pela "câmara de Neubauer", para o volume final de $10 \mathrm{~mL}$ para o experimento in vitro e $50 \mathrm{~mL}$ para in vivo.

O B. cocophilus foi extraído $72 \mathrm{~h}$ antes do início dos experimentos de controle biológico, empregando-se a metodologia do Funil de Baermann adaptada de Hussey e Barker (1973), onde $50 \mathrm{~g}$ de solo foram colocadas sobre papel filtro dentro de um funil, adicionando-se $200 \mathrm{~mL}$ de água esterilizada para decantação durante $24 \mathrm{~h}$. Em seguida, os nematoides foram separados dos resíduos, utilizando-se peneira de 200 mesh sobreposta a de 400 mesh e a quantificação do patógeno foi realizada, separando individualmente 25 nematoides por placa, sob microscópio estereoscópico binocular.

Para o experimento com controle biológico in vitro do nematoide $B$. cocophilus foi realizado o plaqueamento em placas de Petri $(\varnothing=5 \mathrm{~cm})$, adicionando-se $10 \mathrm{~mL}$ de suspensão dos microrganismos (isolados de rizobactérias ou fungos), mais 20 nematoides, as placas foram mantidas em câmaras de crescimento na ausência de luz à $28 \pm 2{ }^{\circ} \mathrm{C}$.

A testemunha consistiu de $10 \mathrm{~mL}$ de água esterilizada contendo 20 nematoides. Foram utilizados 19 isolados de Pseudomonas spp., 29 isolados de Bacillus spp. e 27 isolados de Trichoderma spp., em delineamento inteiramente ao acaso com cinco repetições. Após $24 \mathrm{~h}$ foi avaliado o número de nematoide mortos, contabilizados com auxílio do microscópio estereoscópico binocular. Ao final foi calculada a taxa de mortalidade de nematoide segundo Zhang et al. (2016).

O experimento de controle biológico do B. cocophilus in vivo consistiu de seis tratamentos, três isolados de bactérias, dois pertencentes ao gênero Bacillus (B14 e B23), um de Pseudomonas spp. (P23) e três isolados de Trichoderma spp. (T54, T49 e T47). O tratamento testemunha (TI) foi inoculada apenas com $B$. cocophilus e a testemunha absoluta (T0), inoculada apenas com água esterilizada. O delineamento utilizado foi inteiramente ao acaso, com cinco repetições.

As mudas de coqueiro utilizadas no experimento "in vivo" foram híbridos PB 123 (cruzamento das variedades Anão-amarelo da Malásia x Gigante de Renel), aos seis meses de idade, em vasos contendo $5 \mathrm{~kg}$ de solo esterilizado. Cada planta e seu respectivo solo foram inoculados via rega, com $50 \mathrm{~mL}$ de suspensão bacteriana ou de fungos. Após sete dias, cada planta foi inoculada com 150 nematoides, em perfurações de $2 \mathrm{~cm}$ de profundidade no solo ao redor do colo da planta.

As plantas foram mantidas em casa de vegetação, com temperatura entre $26{ }^{\circ} \mathrm{C}$ e $28{ }^{\circ} \mathrm{C}$. A parcela experimental foi constituída por uma muda de coqueiro. Após 30 dias da inoculação com nematoide, foi coletada uma amostra composta de $100 \mathrm{~g}$ de solo de cada vaso, para a análise quantitativa da população de $B$. cocophilus, empregando-se a metodologia do Funil de Baermann. Foi calculada a taxa de mortalidade de nematoide, segundo Zhang et al. (2016).
Os dados foram submetidos à análise de agrupamento As análises foram conduzidas no programa estatístico SPSS 20 e as médias dos diferentes grupos submetidas ao teste de ScottKnott a 5\% de probabilidade.

No experimento "in vivo", após 30 dias da inoculação com B. cocophilus, foram coletadas as duas folhas mais jovens de cada muda de coqueiro e imersas imediatamente em $\mathrm{N}_{2}$ para o armazenamento em condições de congelamento, para avaliação das enzimas de indução de resistência (quitinase e $\beta$-1,3-glucanases) e de estresse oxidativo (peroxidases).

A atividade de quitinase foi estimada de acordo com a metodologia de Nawani e Kapadnis (2005), o ensaio constituiu-se de $1 \mathrm{ml}$ de quitina coloidal a $1 \%(\mathrm{p} / \mathrm{v})$ em tampão fosfato de citrato $(0,1 \mathrm{M}$ com $\mathrm{pH} 5,5)$ e do ácido dinitrosalicílico (DNS), a atividade de quitinase foi mensurada em mU/mL. A atividade da $\beta$-1,3-glucanases seguiu Lever (1972), utilizando-se como tampão $230 \mu \mathrm{L}$ de acetato de sódio $100 \mathrm{mM}(\mathrm{pH} \mathrm{5,0)}$ e como substrato $250 \mu \mathrm{L}$ de laminarina ( $4 \mathrm{mg} \mathrm{mL}^{-1}$ ), adicionando-se $20 \mu \mathrm{L}$ do extrato vegetal e $500 \mu \mathrm{L}$ do ácido 3,5-dinitrosalicílico (DNS), os resultados foram expressos em unidades de absorbância min ${ }^{1} \mathrm{mg}^{-1} \mathrm{de}$ proteína. A atividade da enzima guaiacol peroxidase (GPX) foi determinada segundo a metodologia de Zeraik et al. (2008), com uso de $1 \mathrm{~mL}$ de guaiacol 15,0 mmol $\mathrm{L}^{-1}$ como substrato e de $1 \mathrm{~mL}$ do tampão fosfato $0,1 \mathrm{~mol} \mathrm{~L}$ ${ }^{1}(\mathrm{pH}$ 6,5), acrescentando-se o peróxido de hidrogênio e 50 $\mu \mathrm{L}$ do extrato vegetal, sendo medida a atividade enzimática em $\mathrm{U} \mathrm{mL} \mathrm{mL}^{-1}$. A atividade de polifenol oxidase (PPO) foi determinada de acordo com Hammerschmidt et al. (1982), utilizando-se $10 \mathrm{~mL}$ de tampão fosfato $0,1 \mathrm{M} ; 1,5 \mathrm{~mL}$ de pirogalol $0,05 \mathrm{M} ; 0,5$ peróxido de hidrogênio a $1 \%$ e $0,5 \mathrm{~mL}$ de extrato bruto, o resultado foi expresso em $\mathrm{min}^{-1} \mathrm{~g}^{-1} \mathrm{de}$ proteína.

Os dados das atividades enzimáticas foram submetidos à análise de variância e ao teste $\mathrm{F}$ a $5 \%$ de significância e quando as médias apresentaram diferença significativa foram comparadas pelo teste de Scott-Knott a 5\% de probabilidade, utilizando-se o programa SISVAR versão 5.3.

\section{RESULTADOS}

O isolamento das rizobactérias resultou na obtenção de 48 isolados, sendo 19 pertencentes ao gênero Pseudomonas e 29 de Bacillus. Em relação a Pseudomonas, 56\% apresentaram forma puntiforme, $88 \%$ elevação lisa e $36 \%$ borda ondulada. Quanto à superfície, 64\% apresentaram característica rugosa e 56\% apresentaram consistência viscosa (Figura 1). Para Bacillus, 30\% dos isolados apresentaram forma circular, 93\% elevação lisa e $48 \%$ borda filamentosa. A análise morfológica agrupou 19 isolados diferentes de Pseudomonas e 29 isolados de Bacillus.

A caracterização bioquímica in vitro das rizobactérias revelou que $56 \%$ foram positivas para protease, $44 \%$ solubilizaram fosfato e $10 \%$ produziram sideróforos (Tabela 1).

Neste trabalho os isolados B09, B14, B05, B11, B29, B28, B16, B19, B24, B18, B03, B17, B01, B10, B13, P05, P04, P06, P20, P01, P12, P21, P22, P23, P25, P26, P33 e P41 foram caracterizados como produtores de compostos químicos sendo considerados potencias promissores para o controle biológico do B. cocophilus. 

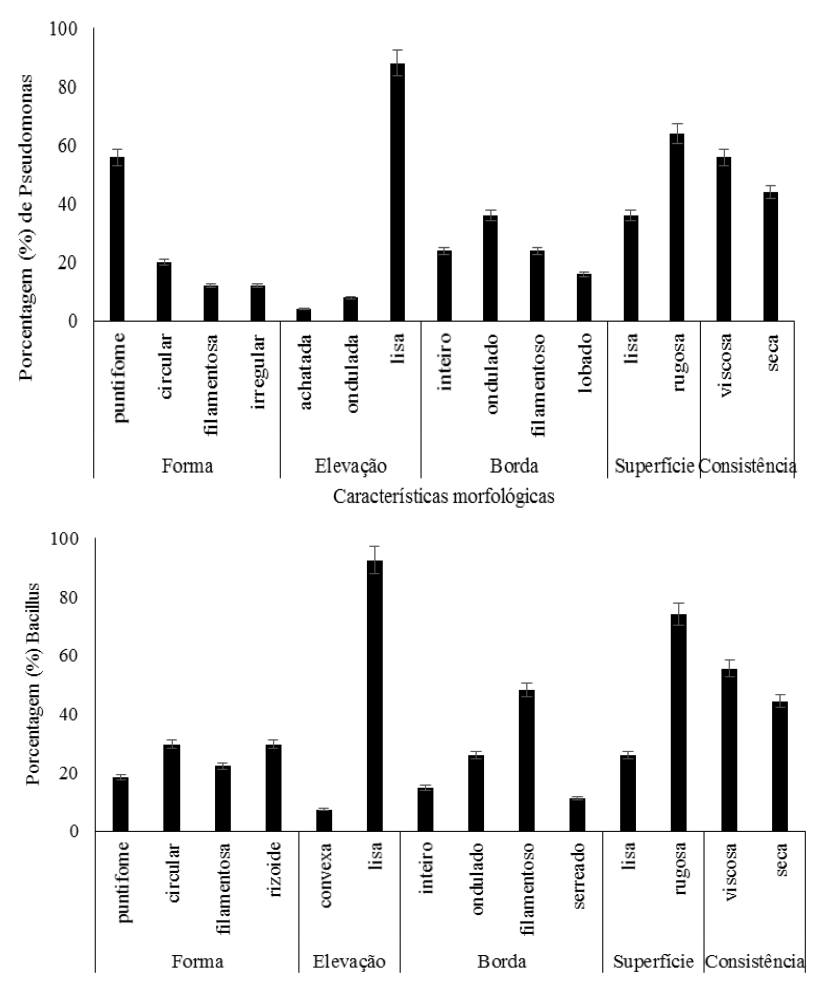

Características Morfológicas

Figura 1. Características morfológicas de isolados de rizobactérias, dos gêneros Pseudomonas e Bacillus, agentes de controle biológico do nematoide Bursaphelenchus cocophilus.

Figure 1. Morphological characteristics of rhizobacteria isolates of the genus Pseudomonas and Bacillus, biological control agents of the nematode Bursaphelenchus cocophilus.

O isolamento de fungos Trichoderma spp. resultou na obtenção de 27 isolados. Em relação à caracterização bioquímica de Trichoderma spp., observou-se que $63 \%$ dos isolados produziram, no mínimo, um dos compostos químicos avaliados, demonstrando o potencial desses fungos para o controle biológico. Foram positivos para quitinase $15 \%$ dos isolados (T47, T48, T49, T74), 26\% para protease (T38, T47, T49, T51, T52, T59, T62), e 41\% foram considerados sideróforos (T36, T43, T49, T51, T54, T55, T56, T57, T58, T63, T74) (Tabela 1).

No experimento de controle biológico do B. cocophilus in vitro pelas rizobactérias, a análise revelou dois grupos diferentes de isolados de Pseudomonas, onde 36\% foram agrupados grupo 1 (G1P), os quais apresentaram maior potencial de controle biológico, pois resultaram em alta taxa de mortalidade de B. cocophilus, $39 \%$ maior do que a testemunha. Para Bacillus foram revelados três grupos distintos e a maior taxa de mortalidade foi verificada no grupo 1 (G1B), com $17,4 \%$ de isolados, que promoveram taxa de mortalidade $52 \%$ maior do que o grupo da testemunha, caracterizando-os como promissores para o controle biológico do nematoide (Tabela 2).

Observou-se que $83 \%$ dos isolados pertencentes ao G1P foram produtores de protease, $50 \%$ foram solubilizadores de fosfato e $33 \%$ foram produtores de sideróforos, enquanto que $60 \%$ dos isolados do G1B foram proteolíticos e solubilizadores de fosfato.

No experimento de controle biológico in vitro de $B$. cocophilus utilizando Trichoderma spp., a análise de agrupamento dividiu os isolados em dois grupos, no grupo 1 foram inseridos $55 \%$ dos isolados, os que resultaram em taxa de mortalidade do nematoide $21 \%$ superior ao grupo da testemunha (grupo 1), ou seja, apresentaram potencial de controle biológico (Tabela 2).

Tabela 1. Caracterização bioquímica de isolados de Bacillus (B), Pseudomonas $(\mathrm{P})$ e Trichoderma $(\mathrm{T})$ produtores de protease, siderórofos, solubilizadores de fosfato e quitinase.

Table 1. Biochemical characterization of Bacillus (B), Pseudomonas (P) and Trichoderma (T) isolates of protease, siderórofos, phosphate solubilizers and chitinase.

\begin{tabular}{|c|c|c|c|c|}
\hline Isolados & Protease & Sideróforos & $\begin{array}{l}\text { Solubilizador de } \\
\text { fosfato }\end{array}$ & Quitinase \\
\hline B01 & + & - & - & NA \\
\hline B03 & + & - & - & NA \\
\hline B05 & + & - & + & NA \\
\hline B09 & + & - & + & NA \\
\hline B10 & + & - & - & NA \\
\hline B11 & + & - & + & NA \\
\hline B13 & + & - & + & NA \\
\hline B14 & + & - & + & NA \\
\hline B16 & + & - & - & NA \\
\hline B17 & + & - & - & NA \\
\hline B18 & + & - & + & NA \\
\hline B24 & + & - & + & NA \\
\hline B28 & + & - & + & NA \\
\hline B29 & + & - & + & NA \\
\hline P01 & + & - & + & NA \\
\hline P04 & + & - & - & NA \\
\hline P05 & + & - & + & NA \\
\hline P06 & - & - & + & NA \\
\hline P12 & + & - & + & NA \\
\hline $\mathrm{P} 20$ & + & - & + & NA \\
\hline $\mathrm{P} 21$ & + & + & + & NA \\
\hline $\mathrm{P} 22$ & + & + & - & NA \\
\hline $\mathrm{P} 23$ & + & + & + & NA \\
\hline P24 & + & - & + & NA \\
\hline $\mathrm{P} 25$ & + & - & + & NA \\
\hline P26 & - & + & + & NA \\
\hline P33 & + & + & + & NA \\
\hline P41 & + & - & + & NA \\
\hline $\mathrm{T} 36$ & - & + & NA & - \\
\hline $\mathrm{T} 38$ & + & - & NA & - \\
\hline $\mathrm{T} 43$ & - & + & NA & - \\
\hline $\mathrm{T} 47$ & + & - & NA & + \\
\hline $\mathrm{T} 48$ & - & - & NA & + \\
\hline T49 & + & + & NA & + \\
\hline T51 & + & + & NA & - \\
\hline T52 & + & - & NA & - \\
\hline T54 & - & + & NA & - \\
\hline T55 & - & + & NA & - \\
\hline T56 & - & + & NA & - \\
\hline T57 & - & + & NA & - \\
\hline T58 & - & + & NA & - \\
\hline T59 & + & - & NA & - \\
\hline T62 & + & - & NA & - \\
\hline $\mathrm{T} 63$ & - & + & NA & - \\
\hline $\mathrm{T} 74$ & - & + & NA & + \\
\hline
\end{tabular}

*Produtor do composto químico (+); não produtor (-) e composto não avaliado (NA).

Os resultados deste trabalho concordam com Zhang et al. (2014) que observaram $90 \%$ de parasitismo de Trichoderma longibrachiatum sobre os cistos de Heterodera avenae in vitro e atribuíram esse fato às atividades das enzimas fúngicas quitinase e proteases. 
Em relação ao experimento controle biológico in vivo os isolados testados (B14, B23, P23, T47, T49 e T54) apresentaram taxa de mortalidade de $B$. cocophilus maior significativamente do que o tratamento testemunha. A análise estatística resultou na formação de três grupos distintos quanto a mortalidade do nematoide, o grupo incluiu a testemunha $(97,2 \%)$, o grupo 2 consistiu dos isolados T54, T49 e T47 $(99,2 \%)$ e o terceiro grupo, os isolados B23, B14 e P23 (100\%).

Tabela 2. Taxa de mortalidade in vitro de Bursaphelenchus cocophilus, causada por isolados dos gêneros Pseudomonas (P), Bacillus (B) e Trichoderma (T).

Table 2. In vitro mortality rate of Bursaphelenchus cocophilus caused by isolates of the genus Pseudomonas (P), Bacillus (B) and Trichoderma $(\mathrm{T})$.

\begin{tabular}{|c|c|c|}
\hline Grupo & Isolados de Pseudomonas & Mortalidade (\%) \\
\hline 1 & P22, P20, P41, P33, P05, P06 & $56,17 \mathrm{~A}$ \\
\hline 2 & $\begin{array}{l}\text { testemunha, P24, P23, P25, P10, } \\
\text { P21, P3, P18, P26, P14, P12, P01, } \\
\text { P04, P17 }\end{array}$ & $19,86 \mathrm{~B}$ \\
\hline Grupo & Isolados de Bacillus & Mortalidade (\%) \\
\hline 1 & B14, B23, B18, B05, B10 & $69 \quad \mathrm{~A}$ \\
\hline 2 & $\begin{array}{l}\text { B15, B16, B11, B19, B04, B09 } \\
\text { testemunha, B20, B27, B29, B28, }\end{array}$ & $46,83 \mathrm{~B}$ \\
\hline 3 & $\begin{array}{l}\text { B24, B25, B22, B8, B17, B6, B12, } \\
\text { B01, B30, B03, B13, B07 }\end{array}$ & 17 \\
\hline Grupo & Isolados de Trichoderma & Mortalidade $(\%)$ \\
\hline 1 & $\begin{array}{l}\text { testemunha, T67, T32, T38, T34, } \\
\text { T62, T14, T64, T33, T55, T43, T36, } \\
\text { T40 }\end{array}$ & $75 \mathrm{~A}$ \\
\hline 2 & $\begin{array}{l}\text { T49, T54, T47, T57, T58, T35, T46, } \\
\text { T59, T56, T51, T63, T37, T74, T50, } \\
\text { T42 }\end{array}$ & $96 \mathrm{~B}$ \\
\hline
\end{tabular}

Knott, $\mathrm{p}>0,05$ ).

Em relação ao experimento controle biológico in vivo os isolados testados (B14, B23, P23, T47, T49 e T54) apresentaram taxa de mortalidade de $B$. cocophilus maior significativamente do que o tratamento testemunha. A análise estatística resultou na formação de três grupos distintos quanto a mortalidade do nematoide, o grupo incluiu a testemunha $(97,2 \%)$, o grupo 2 consistiu dos isolados T54, T49 e T47 (99,2\%) e o terceiro grupo, os isolados B23, B14 e P23 (100\%).

Os microrganismos dos gêneros Bacillus, Pseudomonas e Trichoderma podem ser potenciais agentes de controle de nematoides e entre os mecanismos de parasitismo apresentados, neste estudo, estão a produção de compostos químicos como protease, quitinase, sideróforos e solubilizadores de fosfato.

As mudas de coqueiro inoculadas com o B. cocophilus apresentaram índices superiores a 50\% nas atividades das enzimas, tanto das relacionadas ao estresse oxidativo (PPO e GPX), como das de defesa da planta (QUI e GLUC) quando comparado com o controle. Tais resultados podem evidenciar a indução de defesas das plantas. As mudas tratadas como B23, P14 e T49 e inoculadas com o B. cocophilus resultaram no aumento de $40 \%$ na atividade da enzima QUI. Por outro lado, para a atividade da GLUC os isolados B14 e P23 não diferiram do tratamento inoculado com nematoide $\mathrm{e}$ aumentaram a atividade da enzima $\beta$-1,3-glucanase em 25\% quando comparada a testemunha absoluta (Figura 2).
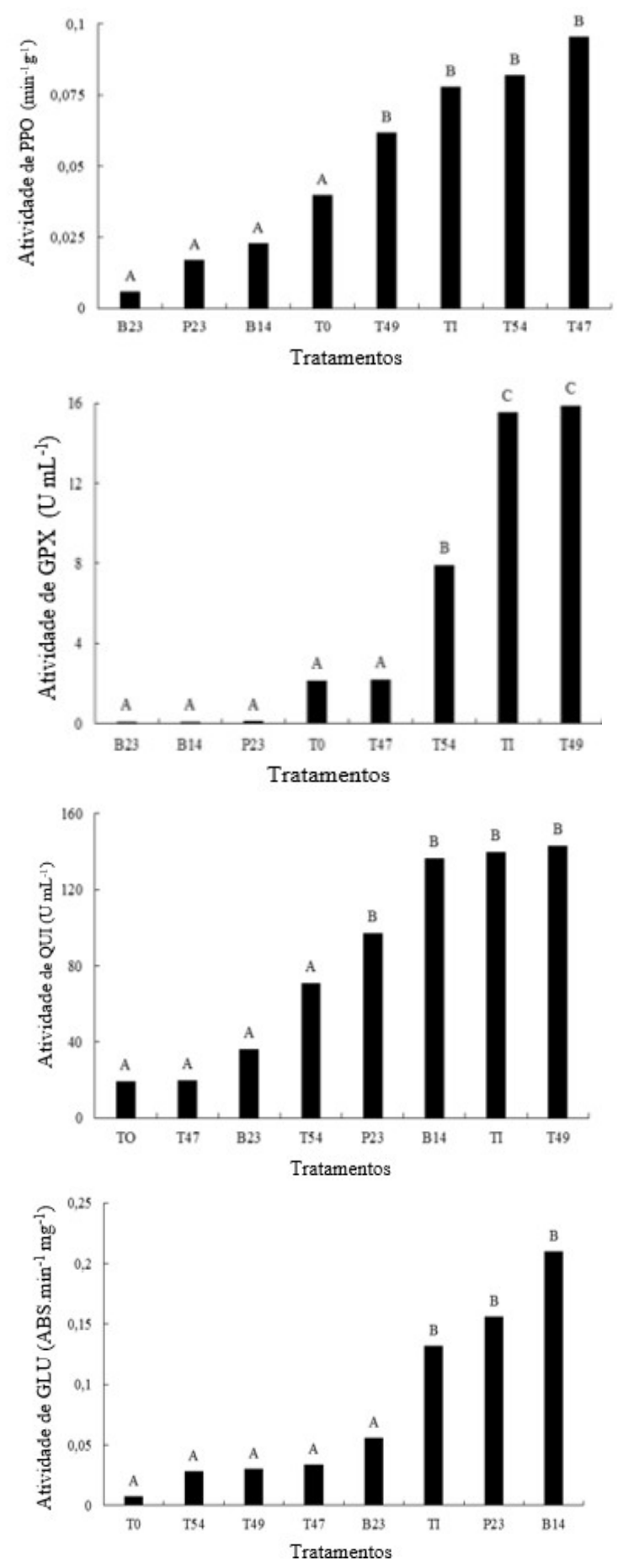

Figura 2. Atividade de enzimas relacionadas ao estresse oxidativo, polifenol oxidase (PPO) e guaiacol peroxidase (GPX), e de enzimas relacionadas a patogênese, quitinase (QUI) e glucanase (GLUC), relacionadas ao controle biológico do Bursaphelenchus cocophilus em mudas de coqueiro, inoculadas com três isolados de rizobactéria (B23, B14 e P23) e três de Trichoderma (T54, T49 e T47). Sendo o controle absoluto (T0) - sem inoculação do nematoide e de microrganismos e o controle negativo (TI) - inoculado apenas com o B. cocophilus. Médias seguidas por uma mesma letra não diferem estatisticamente (Skott-Knott, $\mathrm{p}>0,05$ ).

Figure 2. Activity of enzymes related to oxidative stress, polyphenol oxidase (PPO) and guaiacol peroxidase (GPX), and enzymes related to pathogenesis, chitinase (QUI) and glucanase (GLUC), related to the biological control of Bursaphelenchus cocophilus in coconut, inoculated with three rhizobacterium isolates (B23, B14 and P23) and three of Trichoderma (T54, T49 and T47). Being the absolute control (T0)- without inoculation of the nematoid and microorganisms and negative control (TI)- inoculated only with $B$. 
cocophilus. Averages followed by a statically undifferentiated letter (Skott-Knott, $\mathrm{p}>0,05$ ).

\section{DISCUSSÃO}

A caracterização morfológica e bioquímica indicou as peculiaridades de cada isolado, diferindo-os entre si. A análise morfológica de rizobactérias consiste de uma ferramenta para caracterização e diferenciação dos isolados obtidos, sendo muito utilizada em experimentos que se obtem uma grande diversidade de rizobactérias, como é o caso de ensaios de controle biológico, em que a triagem dos isolados, possíveis agentes de controle biológico, é fundamental para a identificação de cepas eficazes (TU et al., 2013).

As análises bioquímicas dos compostos produzidos por Trichoderma spp. servem para complementar a avaliação dos isolados com potencial para o controle biológico e consistem de uma ferramenta para selecionar os isolados com maior potencial de atividade nematicida, para a utilização no controle biológico do B. cocophilus.

A atividade nematicida de Trichoderma sp. pode estar relacionada com o parasitismo direto que ocorre devido à produção de proteases e de quitinases. Kiewnick; Sikora, (2006) consideraram a produção de quitinases e proteases por Paecilomyces lilacinus, como ação chave para o controle de Meloidogyne incognita em plantas de tomateiro que apresentaram $74 \%$ de redução da população final de nematoides. Sharon et al. (2001) atribuíram à atividade de proteases o parasitismo do estágio infeccioso (J2) de Meloidogyne javanica por Trichoderma harzianum e Sahebani e Hadavi (2008) observaram parasitismo direto de Trichoderma harzianum sobre ovos do nematoide Meloidoyne javanica, atribuindo isto ao aumento da atividade da quitinase extracelular do fungo.

A maioria dos isolados testados foram produtores de protease e solubilizadores de fosfatos, os quais são compostos químicos promissores no controle de doenças de plantas. De acordo com Wei et al. (2014), isolados de Bacillus podem apresentar potencial no controle biológico de nematoides devido ao parasitismo direto de ovos e juvenis, que ocorre pela produção e secreção de enzimas como proteases. Abdallah et al. (2016) observaram a capacidade para solubilização de fosfato por $B$. cereus, que atuou como agente de controle biológico do Fusarium sp. em tomateiro, controlando até $88 \%$ da doença.

Os resultados, do experimento in vitro, mostraram que isolados de Trichoderma spp. são potenciais agentes de biocontrole de $B$. cocophilus, concordando com Zhang et al. (2014) que observaram 90\% de parasitismo de Trichoderma longibrachiatum sobre os cistos de Heterodera avenae in vitro e atribuíram esse fato às atividades das enzimas fúngicas quitinase e proteases.

Os isolados de rizobactérias B14, B23 e P23 testados promoveram maior taxa de mortalidade do B. cocophilus do que os isolados de Trichoderma spp. e a testemunha. A eficiência de rizobactérias no controle de fitonematoides em experimentos in vivo já foi comprovada por diversos trabalhos, como Zhang et al. (2016) avaliaram o potencial de cepas bacterianas de Bacillus cereus (09B18) no controle biológico de Heterodera sp. (cisto do trigo) e relataram redução de $77 \%$ na população do nematoide em casa de vegetação em relação a testemunha, inoculado somente com o patógeno.
Os isolados de Trichoderma spp. podem ser bioagentes promissores no controle de B. cocophilus, outros trabalhos relataram a eficiência no uso de Trichoderma spp. contra outras espécies de fitonematoides como Chaves et al. (2009) que constataram que fungos de Trichoderma spp. foram capazes de reduzir em até $90 \%$ a população final de Radopholus similis (Cobb) Thorne em plantas de bananeira quando comparadas ao controle (plantas de bananeira sem inoculação de $R$. similis).

No experimento in vivo houve aumento das atividades das enzimas PPO, GPX, QUI e GLUC nas mudas de coqueiro inoculadas com o patógeno e com os microrganismos quando comparada a testemunha absoluta (T0). A atividade de peroxidase pode ser relacionada a vários processos de defesa das plantas, como reação de hipersensibilidade, lignificação e suberização, além de atuar como barreira mecânica a toxinas, ou seja, reforçar a parede celular da planta contra a entrada de patógenos e a atividade das PPO envolve a oxidação de compostos fenólicos para quinonas, compostos altamente tóxicos aos microrganismos, podendo resultar em maior grau de resistência à infecção (AGRIOS, 2005).

Higaki e Araújo, (2012) avaliaram a resistência de plantas de algodão aos nematoides Pratylenchus brachyurus e Rotylenchulus reniformis induzida por Bacillus subtilis e abamectina e constataram que a enzima peroxidase pode ser relacionada a resistência da planta a esses nematoides.

Os resultados deste trabalho concordaram com Agrios (2005), em que plantas, quando são atacadas por nematoides, podem ativar tanto enzimas antioxidantes relacionadas ao estresse oxidativo, como GPX e PPO, como as enzimas relacionadas à indução de resistência da planta como quitinases e $\beta$-1,3-glucanses. Youssef et al. (2016) verificaram que o uso dos bioagentes Trichoderma harzianum e Serratia proteamaculans foram capazes de induzir o aumento da atividade das enzimas de defesa peroxidases e catalase em plantas de tomateiro quando desafiadas com o patógeno Rhizoctonia solani, o que pode ratificar as constatações do presente trabalho. $\mathrm{O}$ aumento da atividade enzimática observado após um mês das inoculações dos agentes e do nematoides, possivelmente ocorreu devido a reprodução dos agentes de biocontrole na planta. As peroxidases têm sido estudadas e relacionadas com a indução de defesa da planta no controle de fitonematoides (CHEN et al., 2000; KATSANTONIS et al., 2005).

Contudo, considerando que o anel vermelho do coqueiro ocasiona a morte da planta, medidas de controle preventivas como a inoculação de bioagentes pode se tonar uma importante alternativa constituinte do manejo integrado da doença. Este estudo pioneiro apontou importantes avanços no conhecimento do controle biológico de B. cocophilus em coqueiro, contudo, novos estudos são imprescindíveis para a consolidação do controle biológico preventivamente em plantios comerciais.

\section{CONCLUSÕES}

Os isolados de Bacillus sp. (B41), Pseudomonas sp. (P14) e Trichoderma spp. (T41 e T54) apresentaram-se como potenciais agentes de controle biológico do nematoide Bursaphelenchus cocophilus. 


\section{AGRADECIMENTOS}

À CAPES pela bolsa de doutorado concedida. À equipe técnica de Fitossanidade e à Gerência da empresa Sococo Agroindústria da Amazônia S/A.

À Embrapa Amazônia Oriental, especialmente, à equipe do Laboratório de Fitopatologia.

\section{REFERÊNCIAS}

ABDALLAH, R. A. B.; MOKNI-TLILI, S.; NEFZI, A.; JABNOUN-KHIAREDDINE， H.; DAAMI-REMADI. Biocontrol of Fusarium wilt and growth promotion of tomato plants using endophytic bacteria isolated from Nicotiana glauca organs. Biocontrol, v. 16, p. 80-88, 2016. DOI: http://doi:10.1016/j.biocontrol.2016.03.005.

AFFOKPON, A.; COYNE, D. L.; HTAY, C. C.; AGBÈDÈ, R. D.; LAWOUIN, L.; COOSEMANS, J. Biocontrol potential of native Trichoderma isolates against root-knot nematodes in West African vegetable production systems. Soil Biology, v. 43, p. 600-608, 2011. DOI: http://dx.doi.org/10.1016/j.soilbio.2010.11.029.

AGRAWAL, T.; KOTASTHANE, A. S. Chitinolytic assay of indigenous Trichoderma isolates collected from different geographical locations of Chhattisgarh in Central India. SpringerPlus, v. 1, n. 73, p. 2-10, 2012. DOI: http://dx.doi.org/10.1186/2193-1801-1-73.

AGRIOS, G. N. Plant pathology. 5. ed. Amsterdam: Elsevier, 2005. $922 \mathrm{p}$.

AGROFIT. Busca por produtos formulados. Disponível em: $<$ http://agrofit.agricultura.gov.br/ agrofit_cons/principal_agrofit_cons $>$. Acesso em: 17 jan 2017.

BENITE, A. M. C.; MACHADO, S. P.; MACHADO, B. C. Sideróforos: uma resposta dos microorganismos. Química Nova, Rio de Janeiro, v. 25, n. 6, p. 1155-1164, 2002. DOI: http://dx.doi.org/10.1590/S0100-40422002000700016.

BERG, G.; ROSKOT, N.; STEIDLE, A.; EBERL, L.; ZOCK, A.; SMALLA, K. Plant-Dependent Genotypic and Phenotypic Diversity of Antagonistic Rhizobacteria Isolated from Different Verticillium Host Plants. Applied and environmental microbiology, v. 68 , n. 2, p. 3328 3338, 2002a.

BERG, G.; KRECHEL, A.; DITZ, M.; SIKORA, R. A.; ULRICH, A.; HALLMANN, J. Endophytic and ectophytic potato-associated bacterial communities differ in structure and antagonistic function against plant pathogenic fungi. FEMS Microbiololy Ecology, v. 51, n. 2 p. 215-229, 2002b. DOI: http://doi: 10.1016/j.femsec.2004.08.006.

CHAVES, N. P.; POCASANGRE, L. E.; ELANGO, F.; ROSALES, E.; SIKORA. R. Combining endophytic fungi and bacteria for the biocontrol of Radopholus similis (Cobb) Thorne and for effects on plant growth. Scientia Horticulturae, v. 122, n .3, p. 472-478, 2009. DOI: http://dx.doi.org/10.1016/j.scienta.2009.05.025.

CHEN, C.; BÉLANGER R. R.; BENHAMOU, N.; PAULITZ, T. C. Defense enzymes induced in cucumber roots by treatment with plant growthpromoting rhizobacteria (PGPR) and Pythium aphanidermatum. Physiological and Molecular Plant Pathology, v. 56, p. 13-23, 2000.2 DOI: https://doi.org/10.1006/pmpp.1999.0243.
CHEN, L.; JIANG, H.; CHENG, O.; CHEN, J.; WU, G.; KUMAR, A.; SUN, M.; LIU, Z. Enhanced nematicidal potential of the chitinase pachi from Pseudomonas aeruginosa in association with Cry21Aa. Scientific Reports, v. 5, p. 1-11, 2015. DOI: http://doi:10.1038/srep14395.

FAOSTAT. Food and Agriculture Organization of the United Nations, 2014. Disponível em: $<$ http://faostat.fao.org/site/567>. Acesso em: 17 Jan 2017.

GERBER, K.; GIBLIN-DAVIS, R. M. Association of the Red Ring Nematode and Other Nematode Species with the Palm Weevil, Rhynchophorus palmarum. Journal of Nematology, v. 22, n. 2, p. 143-149, 1990

HAMMERSCHMIDT, R.; NUCKLES, E. M.; KUC，J. Association of enhanced peroxidase activity with induced systemic resistance of cucumber to Colletotrichum lagenarium. Physiology Plant Pathology, v. 20, p. 7382, 1982. DOI: https://doi.org/10.1016/00484059(82)90025-X.

HIGAKI, W. A.; ARAÚJO, F. F. Bacillus subtilis e abamectina no controle de nematoides e alterações fisiológicas em algodoeiro cultivado em solos naturalmente infestado. Nematropica, v. 42, n. 2, 2012.

KATSANTONIS, D.; HILLOCKS, R. J.; GOWEN S. Enhancement of germination of spores of Verticillium dahliae and Fusarium oxysporum f.sp. vasinfectum in vascular fluid from cotton plants infected with the rootknot nematode. Phytoparasitica, v. 33, p. 215-224, 2005. DOI: https://DOI: 10.1007/BF02979858.

KIEWNICK, S.; SIKORA, R. A. Biological control of the root-knot nematode Meloidogyne incognita byPaecilomyces lilacinus strain 251. Biological Control, v. 38, p.179-187, 2006. DOI: http://dx.doi.org/10.1016/j.biocontrol.2005.12.006.

KLEMENT, Z.; RUDOLPH, K.; SANDS, D. C. Methods in Phytobacteriology. Akadémiai Kiadó: Budapest. 1990. $568 \mathrm{p}$.

LEVER, M. A new reaction for colorimetric determination of carbohydrates. Analytical Biochemistry, v. 47, p. 273279, 1972. DOI: http://dx.doi.org/10.1016/00032697(72)90301-6.

LUNGE, A. G.; PATIL, A. S. Characterization of efficient chitinolytic enzyme Producing Trichoderma species: a tool for better antagonistic approach. International Journal of Science, v. 1, n. 5, p. 377-385, 2012.

MACHADO, V.; BERLITZ, D. L.; MATSUMURA, A. T. S.; SANTIN, R. C. M.; GUIMARÃES, A.; SILVA, M. E.; FIUZA, L. M. Rizobactérias como agentes de controle biológico de fitonematoides. Oecologia Australia, v. 16, n. 2, p. 65-182, 2012.

MILLER, G. L. Use of dinitrosalicylic acid reagent for determination of reducing sugar. Analytical Chemistry, v. $31, \quad$ n. 3 , p. 426-428, 1959. DOI: http:DOI: $10.1021 / \mathrm{ac} 60147 \mathrm{a} 030$.

NAWANI, N. N.; KAPADNIS, B. P. Optimization of chitinase production using statistics based experimental designs. Process Biochemistry, v. 40, p. 651-660, 2005. DOI: https://doi.org/10.1016/j.procbio.2004.01.048.

RYU, E. A simple method for differentiation between Grampositive and Gramnegative organisms without staining. Kitazato Archives of Experimental Medicine, v. 17, p. 58-63, 1940. 
SAHEBANI, N.; HADAVI, N. Biological control of the rootknot nematode Meloidogyne javanica by Trichoderma harzianum, Soil Biology and Biochemistry, v. 40, n. 8, p. 2016-2020, 2008. DOI: https://doi.org/10.1016/j.soilbio.2008.03.011.

SANHUEZA, R. M. V.; MELO, I. S. Métodos usados no biocontrole de fitopatógenos. 21 ed. Bento Gonçalves: Embrapa Uva e Vinho, 2007. 141p.

SCHWYN, B. Y; NEILANDS J. B. Universal chemical assay for the detection and determination of siderophores". Analytical biochemistry, v. 160, p. 47-56, 1987. DOI: https://doi.org/10.1016/0003-2697(87)90612-9.

SHARON, E.; BAR-EYAL, M.; CHET,I.; HERRERAESTRELLA， A.; KLEIFELD， O.; SPIEGEL， Y. Biological Control of the Root-Knot Nematode Meloidogyne javanica by Trichoderma harzianum. Phytopathology, v. 91, n. 7, p. 687-693, 2001. DOI: https://doi: 10.1094/PHYTO.2001.91.7.687.

TU, Q.; CHEN, J.; GUO, J. Screening and identification of antagonistic bacteria with potential for biological control of Penicillium italicum of citrus fruits. Scientia Horticulturae, v. 150, p. 125-129, 2013. DOI: http://dx.doi.org/10.1016/j.scienta.2012.10.018.

TZEAN, Y.; CHOU, T. H.; HSIAO, C. C.; SHU, P. Y.; WALTON, J. D.; TZEAN, S. S. Cloning and characterization of cuticle-degrading serine protease from nematode-trapping fungus Arthrobotrys musiformis. Mycoscience, v. 57, p. 136-143, 2016. DOI: http://dx.doi.org/10.1016/j.myc.2015.12.003.

VASCONCELLOS, R. L. F.; SILVA, M. C. P.; RIBEIRO, C. M.; CARDOSO, E. J.B. N. Isolation and screening for Araucaria angustifolia rhizosphere soil. Scientia Agricola, v. 67, n. 6, p. 743-746, 2010. DOI: http://dx.doi.org/10.1590/S0103-90162010000600019.

VITTONE, G. Genetic and Functional Analysis of Siderophores in Trichoderma virens. Tese (Doutorado) Texas, Department of Plant Pathology A; M University, 2008. $97 \mathrm{f}$.

WEI, L.; SHAO, Y.; WAN, J.; FENH, H.; HUANG, H.; ZHOU, Y. Isolation and Characterization of a Rhizobacterial Antagonist of Root-Knot Nematodes. PLoS ONE, v. 9, n. 1, p. 1-7, 2014. DOI: http://dx.doi.org/10.1016/j.biocontrol.2015.08.004.

YOUSSEF, S. A; TARTOURA, K. A.; ABDELRAOUF, G.A. Evaluation of Trichoderma harzianum and Serratia proteamaculans effect on disease suppression, stimulation of ROS-scavenging enzymes and improving tomato growth infected by Rhizoctonia solani. Biological Control, v. 100, n .79-86, 2016. DOI: http://dx.doi.org/10.1016/j.biocontrol.2016.06.001.

ZERAIK, A. E.; SOUZA, F. S.; FATIBELLO-FILHO, O. Desenvolvimento de um spot test para o monitoramento da atividade da peroxidase em um procedimento de purificação. Quimica Nova, v. 31, n. 4, p. 731-734, 2008. DOI: http://dx.doi.org/10.1590/S010040422008000400003.

ZHANG, J.; LI, Z.; YUAN, H.; SUN, B.; LI, H. Biological control of the cereal cyst nematode (Heterodera filipjevi) by Achromobacter xylosoxidans isolate 09X01 and Bacillus cereus isolate 09B18. Biological Control, v. 92, p. $1-6,2016.2$ DOI: http://dx.doi.org/10.1016/j.biocontrol.2015.08.004.

ZHANG, S.; GAN, Y.; XU, B.; XUE, Y. The parasitic and lethal effects of Trichoderma longibrachiatum against Heterodera avenae. Biological Control, v. 72, p. 1-8. 2014

DOI: 